\title{
The 4th Annual "Psyche" Awards for Valuable Contributions to Psychotherapy: Encouraging the Integration of Science and Practice
}

\author{
James C. Overholser ${ }^{1}$ (D)
}

Accepted: 11 May 2021 / Published online: 18 May 2021

(c) The Author(s), under exclusive licence to Springer Science+Business Media, LLC, part of Springer Nature 2021, corrected publication 2021

\begin{abstract}
Psychotherapy relies on a strong integration of theory, empirical research, and clinical experience. Furthermore, publishing journal articles on the diagnosis and treatment of mental illness requires creativity, persistence and a scientific approach. The present article examines recent publications on assessment and diagnosis, case conceptualization and treatment planning and generic issues related to the therapeutic alliance. The article includes a review of papers on common diagnostic problems including anxiety disorders, depression, eating disorders, addictions, and personality pathology. In each of ten categories, the best papers are identified that were published during the past year, and the top article is highlighted as an award winner that should be read by all mental health professionals.
\end{abstract}

Keywords Psychotherapy $\cdot$ Scholarship $\cdot$ Research $\cdot$ Scientist-practitioner

Psychotherapy is a strong and vibrant profession. Effective psychotherapy relies on a sincere integration of a sound theoretical foundation, objective empirical research, and ongoing clinical experience. Mental health experts are trained to set aside their own personal goals and values as they strive to help people manage their own struggles. In many ways, psychotherapy relies on the unselfish caring attitude of a stable and competent person who offers support and serves as a guide during the client's most difficult times. Further, a tremendous amount of patience, persistence, and devotion is required to publish a journal article that includes innovative ideas in the field of psychotherapy. The present article attempts to provide a bit of praise and recognition for the most valuable journal articles published during the year 2020. Such recognition seems especially important during the present pandemic, during which most mental health professionals have struggled to maintain their high standards of performance despite a very challenging year.

The "Psyche Awards" were developed in response to the "award season", when celebrities gather around numerous televised banquets to congratulate themselves for their recent

James C. Overholser

overholser@case.edu

1 Department of Psychology, Case Western Reserve University, 10900 Euclid Avenue, Cleveland, OH 44106-7123, USA songs, movies, and sporting events. Previous awards (Overholser \& Beale, 2018; Overholser, 2019, 2020a, 2020b) acknowledged the important contributions across diverse topics relevant to the assessment and treatment of mental illness. The core of psychotherapy relies on a fiduciary relationship provided by an educated mental health professional, aimed solely at creating lasting benefit for the client. Such selfless work deserves public recognition and praise.

Publishing an article in a scholarly journal requires the persistence to make revisions suggested during the peer review process. The field of psychotherapy is continually improved and refined through the integration of science and practice. The Boulder model is central to the ideals of clinical psychology and mental health care (Overholser, 2007a, 2010a). Unfortunately, there are many professionals who present with a thin veneer, appearing to integrate the science and practice of psychology, while really focused exclusively on research and administrative responsibilities with no involvement in clinical practice (Overholser, 2012). There is a risk when ivory tower academics publish treatment recommendations or guidelines, expecting others to follow, but in reality, these authors have stepped away from their own clinical activities. Instead, the scientist-practitioner remains in the front-lines of clinical practice, devoting their career to the integration of scientific methods with the realities of clinical practice. 
In an attempt to ensure a fair selection of eligible publications, a fairly thorough process was implemented. First, a thorough review of articles published in an academic journal during 2020 were scanned for relevant topics. Papers confronted important issues related to the theoretical understanding, objective assessment, accurate diagnosis, or effective treatment of mental illness. Ideally, papers provided a thoughtful integration of science and practice. Instead of biological factors related to mental illness, it is important for psychologists to retain a clear focus on the mind and mental processes (Overholser, 2003). Eligible papers could center around a comprehensive review of the issues, a systematic review or meta-analysis of previously published studies, a detailed and intriguing clinical case study, or group research designs. Optimal papers were aligned with clinical practice and derived from theory or research in the field, instead of highly controlled research projects that were conducted in analogue environments. Most often, eligible papers included participants that matched the usual clients being treated by mental health professionals. Thus, it is important to access a diverse range of research participants (Arnett, 2008), not restricting data collection to the assessment or evaluation of samples of convenience such as undergraduate college students (Henrich et al., 2010), high school students, community surveys, or anonymous online surveys. Finally, the ideal publication should have broad appeal that seems useful for a wide cluster of mental health professionals, not a narrow focus that might only provide useful information to a small group of mental health professionals.

The review focused on articles published during 2020 in the following 138 scholarly journals: Academic Psychiatry, Acta Psychiatrica Scandinavica, Addictive Behaviors, Aggression and Violent Behavior, American Journal of Alzheimer's Disease and other Dementias, American Journal of Orthopsychiatry, American Journal of Psychiatry, American Journal of Psychotherapy, American Psychologist, Annual Review of Clinical Psychology, Annual Review of Psychology, Archives of Clinical Psychiatry, Archives of sexual Behavior, Assessment, Australian \& New Zealand Journal of Psychiatry, Australian Psychologist, Behavioral Sciences and the Law, Behavior Modification, Behavior Research and Therapy, Behavior Therapy, BMC Psychiatry, British Journal of Clinical Psychology, Canadian Journal of Counselling and Psychotherapy, Canadian Psychology, Clinical Case Studies, Clinical Child and Family Psychology, Clinical Psychology and Psychotherapy, Clinical Psychology Review, Clinical Psychology: Science and Practice, Cognitive and Behavioral Practice, Cognitive Therapy and Research, Comprehensive Psychiatry, Contemporary Buddhism, Contemporary Family Therapy, Counselling and Psychotherapy Research, Counselling Psychology Quarterly, Counselling Psychology Review, Counselor Education and Supervision, Current Directions in Psychological Science,
Current Psychiatry Reports, Death Studies, Depression and Anxiety, Drug and Alcohol Dependence, Ethics and Behavior, European Journal of Psychological Assessment, European Journal of Psychology Applied to Legal Contexts, European Journal of Psychotherapy Counseling and Health, European Journal for Qualitative Research in Psychotherapy, European Psychiatry, Frontiers in Psychology, Gestalt Review, Group Analysis, Group Dynamics, International Forum of Psychoanalysis, International Journal of Alzheimer's Disease, International Journal of Applied Psychoanalytic Studies, International Journal of Cognitive Therapy, International Journal of Eating Disorders, International Journal of Group Psychotherapy, International Journal of Integrative Psychotherapy, International Journal of Intensive Short-Term Dynamic Psychotherapy, International Journal of Law \& Psychiatry, International Journal of Mental Health, International Journal of Psychology and Counselling, International Journal of Psychiatry in Medicine, International Journal of Psychiatry in Clinical Practice, International Journal of Psychological Research, International Journal of Psychotherapy, International Journal of Supervision in Psychotherapy, Irish Journal of Counselling and Psychotherapy, JAMA Psychiatry, Journal of Abnormal Psychology, Journal of Abnormal Child Psychology, Journal of Affective Disorders, Journal of Anxiety Disorders, Journal of Autism and Developmental Disorders, Journal of Attention Disorders, Journal of Behavior Therapy and Experimental Psychiatry, Journal of Clinical Psychiatry, Journal of Clinical Psychology, Journal of Clinical Psychology in Medical Settings, Journal of Clinical Child and Adolescent Psychology, Journal of Consulting and Clinical Psychology, Journal of Contemporary Psychotherapy, Journal of Counseling and Development, Journal of Counseling Psychology, Journal of Family Therapy, Journal of Happiness Studies, Journal of Humanistic Counseling, Journal of Humanistic Psychology, Journal of Loss and Trauma, Journal of Marital and Family Therapy, Journal of Mental Health, Journal of Mental Health Counseling, Journal of Multicultural Counseling and Development, Journal of Nervous and Mental Disease, Journal of Obsessive-Compulsive and Related Disorders, Journal of Personality Assessment, Journal of Personality Disorders, Journal of Psychotherapy Integration, Journal of Rational-Emotive and Cognitive-Behavioral Therapy, Journal of Sexual aggression, Journal of Substance Abuse Treatment, Journal of the American Academy of Child and Adolescent Psychiatry, Mindfulness, Personality and Individual Differences, Personality Disorders: Theory Research and Treatment, Perspectives on Psychological Science, Philosophy Psychiatry \& Psychology, Practitioner Scholar, Professional Psychology, Psychiatric Annals, Psychiatric Clinics of North America, Psychiatric Services, Psychiatry Research, Psychological Science in the Public Interest, Psychology and Psychotherapy, Psychoanalytic Inquiry, 
Psychoanalytic Psychotherapy, Psychoanalytic Psychology, Psychodynamic Practice, Psychological Assessment, Psychological Bulletin, Psychological Medicine, Psychology of Addictive Behaviors, Psychosis, Psychotherapy, Psychotherapy Research, Rorschachiana, Scandinavian Journal of Behaviour Therapy, Scandinavian Journal of Psychology, the Behavior Analyst, the Clinical Gerontologist, the Clinical Supervisor, the Counseling Psychologist, the Psychotherapy Bulletin, Training and Education in Professional Psychology, and Transactional Analysis Journal.

Despite this extensive search process, there is still a chance that some high-quality papers may have been omitted from the selection and nomination process. The goal was to find papers that integrated the science and practice of psychology, and share new ideas that could help to improve psychotherapy. Ideally, the best papers would have broad appeal and remain relevant to psychotherapists even if the topic falls beyond their specific area of expertise. Additional articles that may have been missed or that had been published in other journals were included in the review and selection process, having been identified through a supplemental search for each award category. The massive list of publications was then narrowed down to 182 articles. Then, the editor-in-chief narrowed the list down to the final four articles deemed best to represent each of the ten award categories. However, in most categories this year, it was difficult to reduce the selection to the final four papers, so a fifth article was included in the selection process. Once the final list was created, a panel of four expert judges, including licensed health care providers, members of the editorial board and former award winners, reviewed nominated papers and rank ordered each paper within the assorted categories.

\section{Most Valuable Contribution to Psychological Assessment or Psychiatric Diagnosis}

Psychological assessment lays the foundation for an accurate diagnosis. When the diagnosis has been identified, it becomes easier to devise an effective plan for treatment. Thus, research on various diagnostic categories can help to improve the assessment of psychopathology and refine the delivery of clinical services. The award for most valuable paper requires a clear focus on clinical matters, and if the article has been based on a research study, it involves medical patients or psychiatric clients who are seeking services for their social impairment, cognitive problems or emotional distress. The nominees are ....

Becker-Haimes, E., Tabachnick, A., Last, B., Stewart, R., Hasan-Granier, A., \& Beidas, R. (2020). Evidence base update for brief, free, and accessible youth mental health measures. Journal of Clinical Child \& Adolescent Psychology, 49(1), 1-17.
Fabiano, F., \& Haslam, N. (2020). Diagnostic inflation in the DSM: A meta-analysis of changes in the stringency of psychiatric diagnosis from DSM-III to DSM-5. Clinical Psychology Review, 101889.

Flett, G., Hewitt, P., \& Nepon, T. (2020). The Self-Generated Stress Scale: Development, psychometric features, and associations with perfectionism, self-criticism, and distress. Journal of Psychoeducational Assessment, 38(1), 69-83.

Moscarelli, M. (2020). A major flaw in the diagnosis of schizophrenia: What happened to the Schneider's first rank symptoms. Psychological Medicine, 50(9), 1409-1417.

Powell, M., \& Brubacher, S. (2020). The origin, experimental basis, and application of the standard interview method: An information-gathering framework. Australian Psychologist, 55, 645-659.

And the winner is .... Emily Becker-Haimes and colleagues for the valuable contribution to evidence-based assessment. The comprehensive review summarized and rated the psychometric properties of measures designed to assess anxiety, depression, mania, trauma, psychosis and other forms of mental illness. The paper includes a hyperlink to supplementary materials, a comprehensive table that can be downloaded with detailed summaries of the various measures and links to their online sources. According to the author (Emily Becker-Haimes, personal communication, February 23, 2021): "Identifying accurate, brief, free, and accessible assessment tools for youth mental health is critical—unlike medicine, we do not have blood tests or imaging we can use to identify who needs treatment and monitor whether treatment is working. Instead, we often rely on the use of standardized questionnaires to detect mental health treatment targets and monitor treatment progress. This review provides a critical resource of the current landscape of short and free measures that exist to assess a wide range of youth mental health concerns. Our findings also point to several major gaps in the literature, including the need for more brief and free assessment tools on disordered eating, suicidality, psychosis, and substance use and more work around how to support therapists to use these free tools to monitor treatment progress".

\section{Most Valuable Contribution to Case Formulation and Treatment Planning}

Effective psychotherapy requires a thoughtful plan to guide the sessions. Case conceptualization and treatment planning are the most complex skills that underlie the process of treatment. However, very little has been written to provide guidance to the novice therapist, helping them to develop skill in planning and implementing treatment strategies that extend across multiple sessions. The optimal papers share valuable insights into the struggles that are commonly experienced by 
psychiatric patients and helps clinicians to guide their plans for treatment. The nominees are ....

Gazzillo, F., \& Dimaggio, G. (2020). Case formulation and treatment planning: How to take care of relationship and symptoms together. Journal of Psychotherapy Integration, https://doi.org/10.1037/int0000185

Geurtzen, N., et al. (2020). Patients' perceived lack of goal clarity in psychological treatments: Scale development and negative correlates. Clinical Psychology and Psychotherapy, 27, 915-924.

Goldberg, J., \& Flett, G. (2020). What celebrity case studies can teach about clinical formulation of mental health conditions. Journal of Psychology, 154 (8), 662-679.

Padesky, C. (2020). Collaborative case conceptualization: Client knows best. Cognitive and Behavioral Practice, 27, 392-404.

Rizvi, S., \& Sayrs, J. (2020). Assessment-driven case formulation and treatment planning in dialectical behavior therapy: Using principles to guide effective treatment. $\mathrm{Cog}$ nitive and Behavioral Practice, 27(1), 4-17.

And the winner is .... Christine Padesky for her valuable contribution to case conceptualization. The article centers around two essential strategies for engaging clients in a collaborative planning session. Case examples are used to clarify the thoughtful procedures involved in understanding client struggles and developing a useful plan for treatment. According to the author (Christine Padesky, personal communication, April 6, 2021): "Most therapists are taught to do case conceptualization in their own heads, often between sessions. This can lead to dry, academic formulations. In this article I provide detailed therapist-client dialogues to illustrate a more dynamic case conceptualization approach. Two types of case conceptualization are modeled. One describes interacting features of client issues and illustrates how small changes can lead to big overall improvements. The other helps clients identify triggers and maintenance factors for recurrent problems so clients can see the benefits of trying something new. Both are done with active client involvement and can incorporate client strengths. When clients participate in writing out their own case conceptualization, it usually fosters hope and an eagerness to participate actively in co-creating an effective treatment plan. I hope this article helps therapists become more collaborative, client-centered, and strengths-based in their therapy from start to finish in order to help clients become their own architects of change."

\section{Most Valuable Contribution to the Therapeutic Relationship}

The therapeutic relationship is essential for all forms of treatment. First highlighted by Carl Rogers, the components of a strong therapeutic relationship remain central to effective psychotherapy today (Overholser, 2007b). All schools of psychotherapy have expressed the importance of a sound alliance between therapist and client. Without a good therapeutic relationship, clients are less likely to benefit from therapy, less likely to respond to the therapeutic intervention, and more likely to discontinue services prematurely. The award highlights the value of the therapeutic relationship and clarifies strategies that can be used to develop, enhance or repair the collaborative bond between therapist and client. The nominees are ....

Fahlgren, M., Berman, M., \& McCloskey, M. (2020). The role of the therapeutic alliance in therapy for adults with problematic aggression and associated disorders. Clinical Psychology and Psychotherapy, 27, 858-886.

Kadur, J., Lüdemann, J., \& Andreas, S. (2020). Effects of the therapist's statements on the patient's outcome and the therapeutic alliance: A systematic review. Clinical Psychology \& Psychotherapy, 27(2), 168-178.

von Unwerth, M. (2020). Listening to the patient: A perspective from narrative medicine. International Journal of Psychiatry in Medicine, 55(1), 16-24.

Wilmots, E., Midgley, N., Thackeray, L., Reynolds, S., \& Loades, M. (2020). The therapeutic relationship in cognitive behaviour therapy with depressed adolescents: A qualitative study of good-outcome cases. Psychology and Psychotherapy: Theory, Research and Practice, 93(2), 276-291.

Wu, M., \& Levitt, H. (2020). A qualitative meta-analytic review of the therapist responsiveness literature: Guidelines for practice and training. Journal of Contemporary Psychotherapy, 50, 161-175.

And the winner is .... Max $\mathrm{Wu}$ and Heidi Levitt for their meta-analysis of 75 articles that examined therapist responsiveness. The article examines in detail various components of therapist responsiveness, such as remaining attuned to the client's distress, adapting therapy to support the client's goals, and noticing and accepting responsibility for any disruptions in the therapeutic bond. The article includes a wealth of advice to help guide the process that flows through most psychotherapy sessions. According to the authors (Heidi Levitt, personal communication, February 28, 2021): "This paper integrates research findings related to responsiveness from quantitative and qualitative methods as well as from the clinical observation of cases. This integrative meta-analysis was developed as an alternative to the methods historically used in our field to develop clinical practice guidelines and recommendations for practice. These methods have tended to (1) focus on approaches to therapy, and interventions rather than relational factors (despite that the leading factors contributing to client efficacy are relational factors, such as empathy and the therapeutic alliance), and (2) be based heavily or exclusively in quantitative meta-analytic research of randomized clinical trials. Our goal in this meta-analysis was to develop an innovative 
method that could model the development of clinical guidelines based on a comprehensive consideration of the entire literature on responsiveness. The consideration of findings from varied forms of analysis increased our attunement to how factors might be enacted in therapy. As a result, central findings on responsiveness are summarized in guidelines that have clinical utility within the moment-by-moment process of therapy and provides guidance for clinical in-session decision-making."

\section{Most Valuable Contribution to Understanding Stress, Anxiety or Trauma}

For many people regardless of their age, anxiety disorders can be disruptive if not disabling. When anxiety reaches diagnosable levels, the person may rely on tendencies to avoid difficult situations. If forced to confront their fear, they may try to escape the situation as quickly as possible. These maladaptive coping strategies often serve to perpetuate and exacerbate the person's underlying fear. Thankfully, most anxiety disorders can be treated effectively with established treatment protocols. The award recognizes important advances in the treatment of stress, anxiety or trauma, based on an integration of science and practice. The nominees are

Bokma, W. et al. (2020). A clinical staging approach to improving diagnostics in anxiety disorders: Is it the way to go? Australian and New Zealand Journal of Psychiatry, 54 (2), 173-184.

Farquhar, K., \& Caiazza, R. (2020). Cognitive behavioral therapy for hoarding disorder in an older female. Clinical Case Studies, 19(3), 205-221.

Fischer, C., Heider, J., Schröder, A., \& Taylor, J. (2020). "Help! I'm afraid of driving!" Review of driving fear and its treatment. Cognitive Therapy and Research, 44, 420-444.

Glas, G. (2020). An enactive approach to anxiety and anxiety disorders. Philosophy, Psychiatry and Psychology, 27 (1), 35-50.

Stewart, K., Sumantry, D., \& Malivoire, B. (2020). Family and couple integrated cognitive-behavioural therapy for adults with OCD: A meta-analysis. Journal of Affective Disorders, 277, 159-168.

And the winner is .... Carolin Fischer and colleagues for their review of strategies to overcome driving phobias. Anxiety while driving is a common problem, and the article examines the best strategies for the assessment and treatment of driving fears. The paper includes aspects of technological tools that may be available to assist in exposure therapy plans. According to the author (Carolin Fischer, personal communication, February 24, 2021): "The concept of driving fear caught my attention many years ago when writing my master's thesis in Clinical Psychology. Since then,
I stuck with the topic and discovered the interface between basic and applied research to be especially interesting and promising. Until then, there was little research done in this area which allowed for various research questions. It even resulted in a very valuable scientific collaboration half-way around the globe, between Germany and New Zealand."

\section{Most Valuable Contribution to Understanding Depression or Suicide Risk}

Depression is perhaps the most severe form of mental illness that can be found in a wide spectrum to adolescents and adults. Depression seems widespread, given the troubling events that have occurred recently, ranging from political unrest, racial injustice, and a medical pandemic. It seems essential for researchers and clinicians to focus on improving the scientific understanding and optimal treatment of depression. If left unchecked, depression can reach severe and disabling levels. Further, the combination of severe depression with hopeless expectations for the future can push a distressed individual toward suicidal actions. The award recognizes recent advances in understanding depression and suicide risk and provides ideas for how these problems can be treated effectively. The nominees are ....

Essau, C., de la Torre-Luque, A., Lewinsohn, P., \& Rohde, P. (2020). Patterns, predictors, and outcome of the trajectories of depressive symptoms from adolescence to adulthood. Depression and Anxiety, 37(6), 565-575.

Fox, K., et al. (2020). Interventions for suicide and selfinjury: A meta-analysis of randomized controlled trials across nearly 50 years of research. Psychological Bulletin, 146 (12), 1117-1145.

Jurinec, N., \& Schienle, A. (2020). Utilizing placebos to leverage effects of cognitive-behavioral therapy in patients with depression. Journal of Affective Disorders, 277, 779-784.

Liu, R., Bettis, A., \& Burke, T. (2020). Characterizing the phenomenology of passive suicidal ideation: A systematic review and meta-analysis of its prevalence, psychiatric comorbidity, correlates, and comparisons with active suicidal ideation. Psychological Medicine, 50(3), 367-383.

Taylor, A., Tallon, D., Kessler, D., Peters, T., Shafran, R., Williams, C., \& Wiles, N. (2020). An expert consensus on the most effective components of cognitive behavioural therapy for adults with depression: A modified Delphi study. Cognitive Behaviour Therapy, 49 (3), 242-255.

And the winner is .... Kathryn Fox and colleagues for their meta-analysis of 591 publications on various interventions for suicide and self-injury. The review is thoughtful and thorough, but explains how there has been only modest, if any, improvement over the years. According to the authors (Kathryn Fox \& Xieyining Huang, personal communication, 
March 14, 2021): "As researchers and clinicians, we had a vague sense of what treatments work best to reduce suicidal thoughts and behaviors. However, we were often confused by contradictory evidence from individual papers and metaanalyses that were relatively narrow in scope (e.g., focusing on a few specific interventions, populations, suicide outcomes). To help with this confusion, we conducted a comprehensive meta-analysis summarizing all existing randomized controlled trials that assessed suicide and self-injury outcomes to help us make sense of the efficacy of existing interventions. The findings were surprising and sobering: all existing interventions produced similarly small effects, and no interventions were significantly and consistently better than others. There are many takeaways from the findings, but we think the field will benefit the most from prioritizing the identification of common and necessary causes of suicide to better inform treatment targets."

\section{Most Valuable Contribution to Eating, Obesity, and Eating Disorders}

Eating is necessary for survival, but for some individuals it can become the center of their mental or emotional struggles. Psychological problems related to eating typically focus on either extreme: eating too much or eating too little. The award focuses on articles that reviewed or conducted research on eating problems and shed new light on the treatment of obesity, anorexia, bulimia, or binge-eating. Eligible reports are derived from clinical practice instead of examining "normal" eating patterns that might be observed in college students, high school students or community samples. The nominees are ....

Atwood, M., \& Friedman, A. (2020). A systematic review of enhanced cognitive behavioral therapy (CBT-E) for eating disorders. International Journal of Eating Disorders, 53(3), 311-330.

Hilbert, A., Petroff, D., Herpertz, S., Pietrowsky, R., Tuschen-Caffier, B., Vocks, S., \& Schmidt, R. (2020). Metaanalysis on the long-term effectiveness of psychological and medical treatments for binge-eating disorder. International Journal of Eating Disorders, 53, 1353-1376.

McClelland, J., Robinson, L., Potterton, R., Mountford, V., \& Schmidt, U. (2020). Symptom trajectories into eating disorders: A systematic review of longitudinal, nonclinical studies in children/adolescents. European Psychiatry, 63(1), e60, 1-11.

Patmore, J. (2020). Therapist self-disclosure in the treatment of eating disorders: A personal perspective. Journal of Clinical Psychology, 76(2), 266-276.

Wadden, T., Tronieri, J., \& Butryn, M. (2020). Lifestyle modification approaches for the treatment of obesity in adults. American Psychologist, 75(2), 235-251.
And the winner is .... Tom Wadden and colleagues for their paper on lifestyle changes needed for weight loss and ongoing maintenance in adults. The authors confront the common need for dietary changes, increased physical activity and frequent monitoring of both food intake and caloric expenditure. A spectrum of useful ideas are offered to encourage lifestyle modification that can persist. According to the author (Tom Wadden, personal communication, April 8, 2021): " "In preparing our paper, we were fortunate to be able to draw upon an exhaustive systematic review published in 2013 as part of the revised Guidelines for the Management of Overweight and Obesity in Adults. It provided a clear assessment of the effectiveness of traditional behavior treatment, delivered in-person. Our greatest challenge with the review was in comparing the results of this approach, which has been studied for 50 plus years, with the benefits of newer digitally-delivered interventions, which engage participants in a totally different manner. Attendance of traditional treatment sessions has been replaced by counting participants' log-ins or text messages. Digitally-delivered approaches, though somewhat less effective than in-person interventions, are certainly more convenient, disseminable, and cost effective and have been absolutely critical during the COVID-19 pandemic."

\section{Most Valuable Contribution to Understanding Personality and Its Disorders}

Personality captures a wide spectrum of qualities and traits that are usually considered to develop during childhood, become firmly entrenched by the end of adolescence, and remain stable throughout adulthood. Some troubling personality traits can cause distress to the individual or impairment in social functioning. Personality disorders are often misunderstood and easily missed in a routine psychological assessment. When a personality disorder is present, it usually disrupts the ability of psychological treatments to produce changes in an efficient manner. The award recognizes the latest advances in personality disorder research and how these findings can be used to guide plans for treatment. The nominees are ....

Crisp, H., \& Gabbard, G. (2020). Principles of psychodynamic treatment for patients with narcissistic personality disorder. Journal of Personality Disorder, 34, 143-158.

Sorensen, K., Wilberg, T., Berthelsen, E., \& Rabu, M. (2020). Subjective experience of the origin and development of avoidant personality disorder. Journal of Clinical Psychology, 76, 2232-2248.

Valentino, V., Centonze, A., Inchausti, F., MacBeth, A., Popolo, R., Ottavi, P., ... \& Dimaggio, G. (2020). Addressing maladaptive interpersonal schemas, poor metacognition 
and maladaptive coping strategies in Avoidant Personality Disorder: The role of experiential techniques. Psychology Hub, 37(1), 19-28.

Weinberg, I., \& Ronningstam, E. (2020). Dos and Don'ts in treatments of patients with Narcissistic Personality Disorder. Journal of Personality Disorders, 34(Supplement), 122-142.

Wheaton, M., \& Ward, H. (2020). Intolerance of uncertainty and obsessive-compulsive personality disorder. Personality Disorders: Theory, Research, and Treatment, 11 (5), 357-364.

And the winner is .... Igor Weinberg and Elsa Ronningstam for their informative and pragmatic review of useful treatment strategies when a client has a narcissistic personality. The article summarizes a mix of useful strategies that provide helpful guidance for many different types of clients (e.g., help clients to identify realistic goals for therapy, promote a sense of agency in the client, encourage tolerance of uncertainty). According to the authors (Igor Weinstein, personal communication, February 22, 2021): "In 2009, I was looking for practical principles of treatment for patients with narcissistic personality disorder. The literature on pathological narcissism is a voluminous one, though at that time it offered only very general suggestions for effective treatment. Using this literature as a starting point, I teamed up with Dr. Elsa Ronningstam and started examining what worked in our clinical practices with these patients. Our conclusions turned into the Dos and Don'ts paper."

\section{Most Valuable Contribution to Professional Stress and Burnout}

The work of a mental health professional can become demanding, draining, and disillusioning. Over the years, many skilled mental health professionals can encounter personal struggles caused by the stress of their job, difficulties with co-workers, and struggles trying to help some clients. Occupational stress and career burnout pose a risk to the therapists who provide the frontlines work in mental health care. The award recognizes research or review articles that help to improve the identification, management, or prevention of stress and burnout by health care providers. Nominees are ....

Beks, T., \& Doucet, D. (2020). The role of clinical supervision in supervisee burnout: A call to action. Emerging Perspectives, 4(2), 36-50.

Hou, J-M., and Skovholt, T. (2020). Characteristics of highly resilient therapists. Journal of Counseling Psychology, 67 (3), 386-400.

Jaremka, L., Ackerman, J., Gawronski, B., Rule, N., Sweeny, K., Tropp, L., ... \& Vick, S. (2020). Common academic experiences no one talks about: Repeated rejection, impostor syndrome, and burnout. Perspectives on Psychological Science, 15(3), 519-543.

Yang, Y., \& Hayes, J. (2020). Causes and consequences of burnout among mental health professionals: A practiceoriented review of recent empirical literature. Psychotherapy, 57 (3), 426-436.

And the winner is .... Ying Yang and Jeff Hayes for their review of burnout experienced by mental health professionals. The article explores the causes and effects of professional burnout, and explains strategies that can help to prevent its development (e.g., prioritize self-care, seek support from friends and colleagues). According to the authors (Ying Yang, personal correspondence, March 2, 2021): "Burnout is a common occupational hazard for psychotherapists, and this paper was a two-year labor of love for our colleagues who contend with burnout while working to improve the lives of others. By reviewing 10 years' worth of research, we hope to advance the field's understanding of burnout and provide helpful information to clinicians who are experiencing, or are seeking to prevent, burnout."

\section{Most Valuable Contribution to the Treatment of Couples, Families, or Groups}

Humans are social beings and can only survive because of their bonds with other people. These notions underlie the valuable contributions made throughout Alfred Adler's productive career (Overholser, 2010b, 2013a, 2013b). Thus, it is important to get along with others, inside the family as well as the broader community. Most forms of psychotherapy emphasize, directly or indirectly, the importance of protecting, repairing, and utilizing close interpersonal relationships. The role of social interactions becomes more prominent when several people are present during the therapy session. This award highlights contributions that improve the ability of therapists to provide therapy with couples, families or groups. Nominees include ....

Bradbury, T., \& Bodenmann, G. (2020). Interventions for couples. Annual Review of Clinical Psychology, 16, 99-123.

Crisp, H., \& Gabbard, G. (2020). Principles of psychodynamic treatment for patients with narcissistic personality disorder. Journal of Personality Disorders, 34 (supplement), 143-158.

Northey, W., \& Gehart, D. (2020). The condensed MFT Core Competencies: A streamlined approach for measuring student and supervisee learning using the MFT Core Competencies. Journal of Marital and Family Therapy, 46(1), 42-61.

Pitillas, C. (2020). Common therapeutic elements of interventions aiming at enhancing parent-child early relationships. Psychoanalytic Psychology, 37 (1), 28-36. 
Weinberg, H. (2020). Online group psychotherapy: Challenges and possibilities during COVID-19 - A practice review. Group Dynamics: Theory, Research, and Practice, 24(3), 201-211.

And the winner is .... Tom Bradbury and Guy Bodenmann for their thoughtful review of couple's therapy. The comprehensive review paper examines a wide spectrum of interventions and emphasizes the gains that can be observed from behavioral and emotion-focused treatments for marital distress. According to the authors (Tom Bradbury, personal communication, February 23, 2021): "In our efforts to synthesize the vast literature on interventions for couples, Guy and I worked to highlight the impressive progress that our colleagues have made while balancing that progress against some notable challenges that remain to be addressed. Research on how to help couples has accelerated rapidly in the past two decades, leading to tremendous opportunities for practitioners to now enrich, distill, and adapt some core principles for their daily practices. We were especially pleased to see the maturation of this crucial discipline, and writing this review left us excited and optimistic about the achievements and tasks that are now coming into focus on the horizon."

\section{Most Valuable Contribution to Novel Advancements in Psychotherapy}

Traditional talk therapy has persisted in slightly modified forms for more than 130 years. However, it is important for the field to push forward in new and creative ways, expanding the form and content of therapy sessions. Innovative approaches help the field to seek outside-the-box changes that may offer new insights into the process of change. These creative approaches for improving psychotherapy tend to focus on the mind and mental processes, while trusting that our psychiatric colleagues will focus on the latest advances in biomedical approaches. The award highlights novel advances in psychological treatment that extend beyond the traditional exchange of words (Overholser, 2004). Nominees are ....

Arnon, S., Fisher, P., Pickover, A., Lowell, A., Turner, J., Hilburn, A., ... \& Hamilton, A. (2020). Equine-Assisted Therapy for veterans with PTSD: Manual development and preliminary findings. Military Medicine, 185(5-6), e557-e564.

Atherton, W., Meola, C., \& Pritchard, K. (2020). Innovative Equine Facilitated Psychotherapy intervention for adolescent addiction treatment: A pilot study. International Journal of High Risk Behaviors and Addiction, 9(3) e103877.
Hughes, M., Verreynne, M., Harpur, P., \& Pachana, N. A. (2020). Companion animals and health in older populations: A systematic review. Clinical Gerontologist, 43(4), 365-377.

Mishra, D., Singh, A., Halder, A., Sharma, A., Rao, R. (2020). MEDICATE: Treating depression via game therapy. International Journal of Engineering Applied Sciences and Technology, 5 (1), 274-280.

Nason, E., Trahan, M., Smith, S., Metsis, V., \& Selber, K. (2020). Virtual treatment for veteran social anxiety disorder: A comparison of 360 video and 3D virtual reality. Journal of Technology in Human Services, 38(3), 288-308.

And the winner is .... Erica Nason and colleagues for their paper on video and virtual reality treatments for social anxiety disorder. In a small study, patients with social anxiety disorder were exposed to social interactions in a simulated grocery store using either virtual reality or a 360-degree video platform. Both presentation modalities were found useful in evoking common anxiety symptoms as part of the exposure treatment. According to the authors (Erica Nason, personal correspondence, February 25, 2021): "Technology, such as virtual reality, is rapidly becoming more accessible for researchers and clinicians interested in augmenting existing psychological treatments, such as exposure-based protocols for anxiety disorders and posttraumatic stress disorder. This study focused on comparing participants' responses to two different technological platforms (3-dimensional virtual reality and 360-degree video) in order to examine the relative advantages and disadvantages associated with each approach."

\section{Conclusions}

Each award winner deserves recognition and praise for their valuable contributions to the field of psychotherapy. Despite the volumes of journal articles that are published each year, only a handful of articles in each area truly deserve recognition. The past year was incredibly productive with quite an array of interesting and useful ideas published across the spectrum of journals. Each award recognizes the important insights gained from a published article that helps to advance the field of psychological treatments. These articles integrate the science and practice of psychology, and they offer guidance for working with a range of client struggles. In many ways, these articles steer the direction of the field toward optimal clinical practice. These articles provide information that appears useful in standard clinical practice and the conclusions appear accurate and modest. In several award categories, the winning paper edged out the second-place nominee by merely a few points.

There were a few additional papers that deserve honorable mention, because they were omitted from the award process 
simply because there were not enough papers to form a new award category. For example, Liebovich et al. (2020) describe a recent case study in which interpretive strategies are used to promote positive growth in a client. A detailed case example is useful to clarify the treatment procedures and demonstrates the use of a single case research design applied to psychodynamic psychotherapy. Another article from a different theoretical orientation also bridged the gap between scientist and practitioner. Swales and Dunkley (2020) summarized the principles of skills assessment as used in Dialectical Behavior Therapy. Instead of a single detailed case report, Swales and Dunkley (2020) explain their assessment strategies using multiple brief case vignettes. The article includes detailed advice that could be useful for many therapists, young and old, to plan and implement effective therapy strategies. The article exemplifies the goal of integrating science and practice to refine psychological treatments. Finally, Jing Lv et al. (2020) shared insights from Buddhist meditations that could help to expand traditional western approaches to psychotherapy. Their systematic review and meta-analysis revealed the potential benefit from therapeutic approaches that encourage a focus on four prosocial attitudes.

In conclusion, the award process was developed to highlight the best journal articles published each year, recognizing the works that provide a thoughtful integration of science and practice. Each of the award-winning articles, along with all of the nominated papers, deserve a thorough reading by all mental health providers.

\section{Editorial Post Script}

As editor-in-chief for the Journal of Psychotherapy, I wish to thank the active members of my editorial board. These experts provide thoughtful reviews of all manuscripts that are submitted for possible publication. During the year 2020, despite the world-wide struggles caused by the COVID-19 pandemic and political factions that disrupted the world, the Journal of Contemporary Psychotherapy received a record number of submissions from a wide range of countries, with many under-represented countries submitting at least one manuscript this past year. Every manuscript is reviewed by at least two expert reviewers, and useful feedback is provided even when manuscripts are rejected.

In addition to the members of the editorial board, I want to thank an extensive list of ad hoc reviewers who provided comments on manuscripts during the past year. The list includes: Steve Abell, Rudy Abi-Habib, Oladayo Ayobami Afolabi, Cemile Akdag Cebi, Annette BoVee Akyurek, Ana Anixo, Shlomo Ariel, Aaron Balick, Catherine Barber, Allison Baier, Jordan Bate, Raymond Bergner, Shamell Brandon, Cyrille Bouvet, William Boyd, Nina Brown, Virginia Brabender, Ana Mafalda Almeida Bruno, David Cain,
Kerry Cannity, Cristophe Cazauvieilh, Charles Cedarburg, Julie Cerel, Jasmine Childs-Fegredo, Aureliano Crameri, Lisa Cerda, Flametta Cosci, Rachel Crook-Lyon, Sarah Danzo, Martin Dorahy, Chantal Bourgault du Coudray, Caitlin Edwards, Gulsen Erden, Stuart Fisher, Espen Folmo, Jasmine Childs-Fegredo, Louis Gamino, Charles Gelso, Rajesh George, Erica Jex Gergely, Giac Giacomantonio, Duncan Gill, William Gottdiener, Eugena Griffin, Naveen Grover, Rudy Abi-Habib, Scott Hall, Jay Hamm, Silvia Hernandez, Thomas Hoffman, Isaac Hooley, Nizar Ismat, Monica Janczak, Dave Jobes, Dominic Julien, Lori Katz, Aaron Kindsvatter, Jens Knutsson, Ioanna Kousteni, Nancy Kosovo, Valerie Krupnick, Jeffrey Kuentzel, Lloyd Laland, Itzhak Lander, Bethany Leonhardt, Duane Lundervold, Paul Lysaker, Christopher McGovern, Shannon McIntyre, AnnaMaria McLaughlin, Brian Miller, Dawn Moeller, Tomoyuki Nagayama, Hamid Nejat, Lindi Nel, Randy Nobbitt, Christophe Panicheli, Andrej Pec, Alex Piedra, Alberta Pos, Amir Qorbanpoorlafmejani, Amy Przeworski, Katherina Reinecke, Susan Reviere, Josephine Ridley, Sara Schapiro, Elizabeth Shapiro, Sarah Spannagel, Tom Tomaszewski, Tamiko Truelove, Liliana Varman, Jennifer Vellieux, Paul Wong, Manfred Wu, James Yokley, and Allison Zubot. Finally, I want to thank the Long Island Consultation Center, and Sprinter Nature Publications for their ongoing support for the Journal of Contemporary Psychotherapy. Without their leadership and support, there would be no journal and no award. Thank you everyone.

\section{References}

Arnett, J. (2008). The neglected 95\%: Why American psychology needs to become less American. American Psychologist, 63(7), 602-614.

Henrich, J., Heine, S., \& Norenzayan, A. (2010). The weirdest people in the world? Behavioral and Brain Sciences, 33, 61-135.

Liebovich, L., Wachtel, P., Nof, A., \& Zilcha-Mano, S. (2020). "Take a sad song and make it better": What makes an interpretation growth facilitating for the patient? Psychotherapy, 57(3), 400-413.

Lv, J., Liu, Q., Zeng, X., Oei, T. P., Liu, Y., Xu, K., Sun, W., Hou, H., \& Liu, J. (2020). The effect of four Immeasurables meditations on depressive symptoms: A systematic review and meta-analysis. Clinical Psychology Review, 76, 101814.

Overholser, J. C. (2003). Where has all the psyche gone: Searching for treatments that focus on psychological issues. Journal of Contemporary Psychotherapy, 33(1), 49-61.

Overholser, J. C. (2004). Contemporary psychotherapy: Moving beyond a therapeutic dialogue. Journal of Contemporary Psychotherapy, 34(4), 365-374.

Overholser, J. C. (2007). The central role of the therapeutic alliance: A simulated interview with Carl Rogers. Journal of Contemporary Psychotherapy, 37(2), 71-78.

Overholser, J. C. (2007). The Boulder model in academia: Struggling to integrate the science and practice of psychology. Journal of Contemporary Psychotherapy, 37, 205-211. 
Overholser, J. C. (2010). Psychotherapy that strives to encourage social interest: A simulated interview with Alfred Adler. Journal of Psychotherapy Integration, 20(4), 347-363.

Overholser, J. C. (2010). Ten criteria to qualify as a scientist-practitioner in clinical psychology: An immodest proposal for objective standards. Journal of Contemporary Psychotherapy, 40(1), 51-59.

Overholser, J. C. (2012). Behind a thin veneer: What lurks beneath the scientist-practitioner label? Journal of Contemporary Psychotherapy, 42(4), 271-279.

Overholser, J. C. (2013). Technology-Assisted Psychotherapy (TAP): Adapting computerized treatments into traditional psychotherapy for depression. Journal of Contemporary Psychotherapy, 43(4), 235-242.

Overholser, J. C. (2013). A true sense of community has no boundaries: A simulated interview with Alfred Adler. Journal of Individual Psychology, 69(1), 7-23.

Overholser, J. C. (2019). "The nominees for best article ...": Awards for the most valuable papers on psychotherapy in 2018. Journal of Contemporary Psychotherapy, 49(4), 273-281.
Overholser, J. C. (2020). Roll out the red carpet: The third annual awards for contributions to psychotherapy. Journal of Contemporary Psychotherapy, 50(4), 295-304.

Overholser, J. C. (2020). 50 years of JCP: Erudition, evolution, and evaluation. Journal of Contemporary Psychotherapy, 50(2), 87-93.

Overholser, J. C., \& Beale, E. E. (2018). And the winner is.....: Awards for the integration of science and practice in psychology. Journal of Contemporary Psychotherapy, 48(4), 179-187.

Swales, M., \& Dunkley, C. (2020). Principles of skills assessment in Dialectical Behavior Therapy. Cognitive and Behavioral Practice, 27, 18-29.

Publisher's Note Springer Nature remains neutral with regard to jurisdictional claims in published maps and institutional affiliations. 